\title{
Bacterial flora associated with diseased freshwater ornamental fish
}

\author{
Natalia Walczak, Krzysztof Puk, Leszek Guz \\ Department of Fish Diseases and Biology, Faculty of Veterinary Medicine, \\ University of Life Sciences, 20-950, Lublin, Poland \\ nataliawalczak010@gmail.com
}

Received: August 22, 2017

Accepted: December 8, 2017

\begin{abstract}
Introduction: Ornamental fish can suffer from different bacterial diseases. Among them the most prevalent are infections caused by Aeromonas, Shewanella, Citrobacter, Plesiomonas, Edwardsiella, and Pseudomonas. But there is a broad spectrum of rarely identified bacteria which may be causative agents of diseases. The aim of the study was to determine the species of bacteria pathogenic for fish which are prevalent in aquariums. Material and Methods: Bacteria were isolated from infected ornamental fish from pet shops and private aquariums in the Lublin region in 2015 and classified to species using MALDI-TOF MS. Results: A total of 182 isolates from ornamental fish were identified. The most frequent bacteria found in diseased fish were Aeromonas veronii (30.8\% of total number of strains), A. hydrophila (18.7\%), Shewanella putrefaciens (7.1\%), Citrobacter freundii (7.1\%), Pseudomonas spp. (7.1\%), Shewanella baltica (4.9\%), and Plesiomonas shigelloides (3.3\%). Conclusion: Isolated bacterial species are facultative pathogens for fish and humans and may be isolated from fish without apparent symptoms of the disease.
\end{abstract}

Keywords: ornamental fish, fish pathogens, MALDI-TOF MS method, species identification.

\section{Introduction}

The ornamental fish trade is a developing worldwide industry. According to data of the European Pet Food Industry Federation, there are 4,500 species of ornamental freshwater fish and 1,450 species of marine ornamental fish. More than $50 \%$ of ornamental fish originate from Thailand, Japan, China, Malaysia, and Sri Lanka (20). The European Union (EU) is one of the largest importers of ornamental fish (http://www. ornamentalfish.org/wp-content/uploads/EU-Trade-Stats -Report-2015) and the Czech Republic and the Netherlands are reported among the largest European global exporters of ornamental fish. Statistics show that in the EU, Poland holds the seventh place in terms of number of ornamental pet fish (data from 2014, http://www.fediaf.org/facts-figures/), estimated at 280,000 , which means that aquariums are popular in Polish households. The worldwide development of the ornamental fish trade favours the wide spread of their pathogens, such as bacteria, parasites, fungi, and viruses, which are often transported with fish. This increases the risk of human infection. The bacteria most frequently described as fish pathogens are
Aeromonas (28), Edwardsiella (5, 21), Pseudomonas (3, 25), Shewanella (13), Mycobacterium (30), Streptococcus (25), and Flavobacterium (25), of which some are common in Polish waters $(12,15)$. However, there is a risk that fish imported from distant countries are reservoirs of atypical bacteria for Polish environments. These microorganisms can spread uncontrollably during the transfer of fish from one aquarium to another. It results in the emergence of new types of infections in aquatic organisms. These factors contribute to the limited state of knowledge about ornamental fish diseases and their causative agents.

The aim of this study was identification of bacterial species isolated from freshwater ornamental fish obtained from pet shops and private aquariums in the Lublin region.

\section{Material and Methods}

Sampling of freshwater ornamental fish. A total of 62 diseased ornamental fish, belonging to 27 different species, were sampled and transported alive to the laboratory of the Department of Fish Diseases 
and Biology, Faculty of Veterinary Medicine, University of Life Sciences in Lublin, for bacteriological examination during the period from January 2015 to December 2015. The species investigated were Danio rerio $(\mathrm{n}=10)$, Puntigrus tetrazona $(\mathrm{n}=5), \quad$ Carassius auratus $(\mathrm{n}=3)$, Xiphophorus helleri $(\mathrm{n}=3)$, Poecilia reticulata $(\mathrm{n}=5)$, Poecilia sphenops $(\mathrm{n}=2)$, Symphosodon discus $(\mathrm{n}=1)$, Trichogaster trichopterus $(\mathrm{n}=4)$, T. lalius $(\mathrm{n}=1)$, Ancistrus leucostictus $(\mathrm{n}=2)$, Gymnocorymbus ternetzi $(\mathrm{n}=2), \quad$ Pterophyllum scalare $(\mathrm{n}=2)$, Trigonostigma heteromorpha $(\mathrm{n}=2)$, Xiphophorus maculatus $(\mathrm{n}=3)$, Labidochromis caeruleus $(\mathrm{n}=3)$, Paracheirodon innesi $(\mathrm{n}=2)$, Chromobotia macracanthus $(\mathrm{n}=1)$, Microgeophagus ramirezi $(\mathrm{n}=1)$, Betta splendens $(\mathrm{n}=2)$, Tanichthys albonubes $(\mathrm{n}=1)$, Macropodus opercularis $(\mathrm{n}=1)$, Crossocheilus oblongus $(\mathrm{n}=1)$, Pterygoplichthys gibbiceps $(\mathrm{n}=1)$, Hyphessobrycon bentosi $(\mathrm{n}=1)$, Pangio kuhlii $(\mathrm{n}=1)$, Pseudotropheus saulosi $(\mathrm{n}=1)$, and Cichlasoma synspilum x Cichlasoma citrinellum $(\mathrm{n}=1)$. Fish presenting at least one clinical sign of disease (skin ulcerations, abdominal distension, scale protrusion, haemorrhages on skin and fins, fin rot, distortion of body, or lack of appetite) were collected from pet shops and private aquariums located in the Lublin region of Poland.

Bacterial isolation. All diseased fish were euthanised using an overdose of ethyl 3-aminobenzoate methanesulfonate (MS-222, Sigma Aldrich, USA). Samples were taken from the skin ulcers, kidneys, and gills, and streaked on tryptic soy agar (TSA). Plates were then incubated at $28^{\circ} \mathrm{C}$ for $48 \mathrm{~h}$. The strains were subcultured at least twice, or until a homogeneous cell culture was observed.

Identification of species by MALDI-TOF mass spectrometry. MALDI-TOF-MS (Matrix-Assisted Laser Desorption/Ionisation Time of Flight Mass Spectrometry) analysis was used for identification of bacterial species. Isolates were prepared for mass spectrometry according to a standard protocol recommended by the Bruker company.

The isolates from TSA culture were used for mass spectrometry measurements after $48 \mathrm{~h}$ of incubation. Bacterial cells from one single colony were suspended in $300 \mu \mathrm{L}$ of ultra-pure water. The samples were mixed by vortexing vigorously for $1 \mathrm{~min}$, after which $900 \mu \mathrm{L}$ of LC (liquid chromatography) grade ethanol was added. The samples were stored at $-20^{\circ} \mathrm{C}$ until use. These mixtures were centrifuged at $13,000 \mathrm{x} \mathrm{g}$ for $2 \mathrm{~min}$ and residual supernatants were discarded. A total of $50 \mu \mathrm{L}$ of $70 \%$ formic acid was added to the pellet and mixed to resuspend the bacteria for $1 \mathrm{~min}$. Then $50 \mu \mathrm{L}$ acetonitrile was added and the samples were mixed. The solutions were centrifuged at $13,000 \mathrm{x} g$ for $2 \mathrm{~min}$. The supernatants were transferred to a new tube immediately. Processed samples were placed in a 384 steel plate, allowed to dry, and covered with a matrix solution ( $\alpha$-cyano-4-hydroxy cinnamic acid, HCCA)
(Bruker Daltonics, Germany) and air-dried at room temperature.

The protein analysis by MALDI-TOF-MS was performed in an UltrafleXtreme mass spectrometry unit (Bruker Daltonics, Germany). Prior to analysis, the mass spectrometer was externally calibrated with a Bacterial Test Standard (Bruker, Germany) containing previously prepared extract of Escherichia coli DH5 alpha. Spectra were recorded in the positive linear mode at a laser frequency of $20 \mathrm{~Hz}$ within a mass range from 2 to $20 \mathrm{kDa}$. Parameter settings for the instrument were ion source 1 at $25 \mathrm{kV}$, ion source 2 at $18.5 \mathrm{kV}$, lens at $8.5 \mathrm{kV}$, pulsed ion extraction of $250 \mathrm{~ns}$, and no gating, under control of FlexControl software (version 3.0, Bruker Daltonics). In order to assess the reproducibility of MALDI-TOF-MS identification, every strain studied was tested in duplicate (i.e., on two different MALDI-TOF-MS plates run on two different days and two different batches of culture medium).

The MALDI-TOF Biotyper (version 3.0, Bruker Daltonics) has been used to identify microorganisms. For MALDI-TOF-MS analysis, we adapted the score values proposed by the manufacturer: a score $\geq 1.999$ indicated species identification, a score of 1.7-1.999 generally meant a reliable identification of bacteria, and $<1.7$ signified no identification. An isolate was considered correctly identified by MALDI-TOF-MS when $\geq 3 / 4$ spectra had a score $\geq 1.999$ for species or $\geq 1.7$ for genus identification.

\section{Results}

Protein profiles of 210 isolates were studied by the MALDI-TOF MS method. In total 182 isolates were successfully identified. The most frequent bacteria found in diseased fish were Aeromonas veronii $(\mathrm{n}=56$; $30.8 \%$ of total number of strains) and $A$. hydrophila $(\mathrm{n}=34 ; 18.7 \%)$, followed by Shewanella putrefaciens $(\mathrm{n}=13 ; 7.1 \%)$, Citrobacter freundii $(\mathrm{n}=13 ; 7.1 \%)$, Pseudomonas spp. $(\mathrm{n}=12 ; 6.6 \%)$, Shewanella baltica $(\mathrm{n}=9 ; 4.9 \%)$, and Plesiomonas shigelloides $(\mathrm{n}=6$; 3.3\%) (Fig. 1). Among the genus Pseudomonas, eight species were identified: $P$. alcaligines $(\mathrm{n}=1)$, P. putida $(\mathrm{n}=5), P$. mosselii $(\mathrm{n}=1), P$. marginalis $(\mathrm{n}=1), P$. monteilii $(\mathrm{n}=1), P$. koreensis $(\mathrm{n}=1)$, $P$. oleovorans $(\mathrm{n}=1)$, and $P$. nitroreducens $(\mathrm{n}=1)$. The following strains were rarely identified: Acinetobacter junii $(\mathrm{n}=4 ; 2.2 \%)$, Aeromonas caviae $(\mathrm{n}=4 ; 2.2 \%)$, A. lwoffii $(\mathrm{n}=2 ; 1.1 \%)$, and A. media $(\mathrm{n}=2 ; 1.1 \%)$. Colonies defined as rare species were also observed: Listonella anguillarum $(\mathrm{n}=2 ; 1.1 \%)$, Budvicia aquatica $(\mathrm{n}=2 ; 1.1 \%)$, Bacillus cereus $(\mathrm{n}=1 ; 0.5 \%)$, Providencia rettgeri $(\mathrm{n}=1 ; 0.5 \%)$, Edwardsiella tarda $(\mathrm{n}=1 ; 0.5 \%)$, Rhodococcus erythropolis $(\mathrm{n}=1 ; 0.5 \%)$, Brevibacterium casei $(\mathrm{n}=1 ; 0.5 \%)$, Citrobacter murliniae $(\mathrm{n}=1 ; 0.5 \%)$, and Serratia ureilytica $(\mathrm{n}=1 ; 0.5 \%)$. 


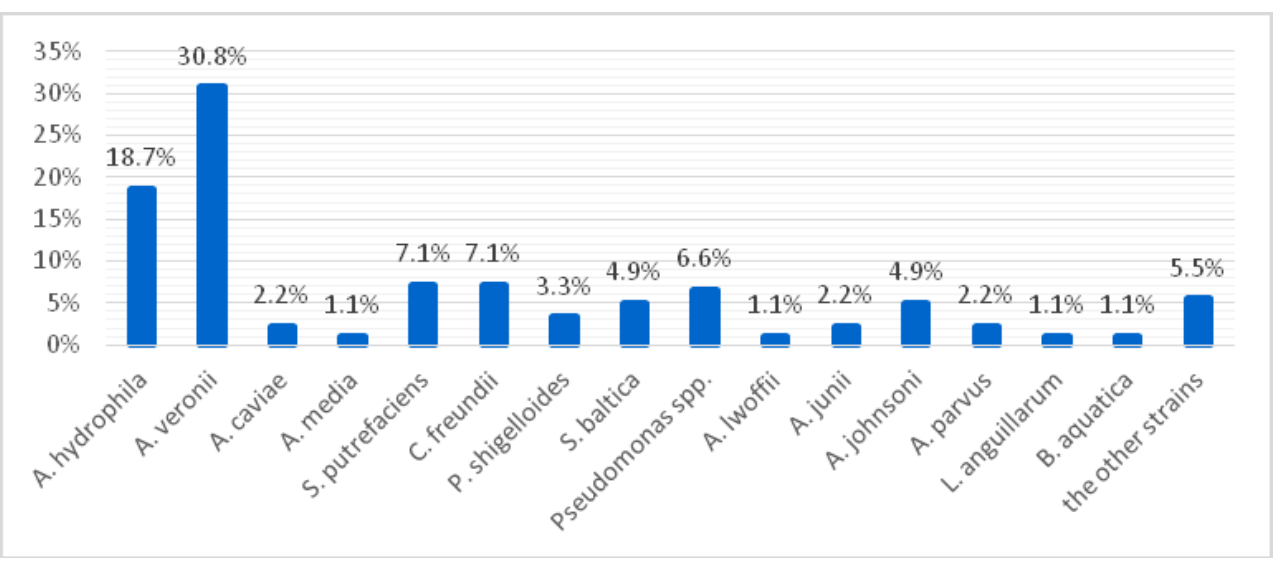

Fig. 1. Percentage of bacteria species isolated from 62 ornamental fish in Lublin region in 2015. The group of "the other strains" comprises samples which contain a single identified species: A. scleromae, B. cereus, B. casei, C. braakii, C. murliniae, C. testosteroni, E. tarda, P. rettgeri, R. erythropolis, and S. ureilytica

\section{Discussion}

Aeromonads are probably the most commonly encountered bacterial pathogens of freshwater fish. Several species may be responsible for motile Aeromonas infections and/or motile Aeromonas septicaemia in ornamental fish. In our study, bacterial infections associated with motile Aeromonas hydrophila were reported in 14 species of fish (D. rerio, X. helleri, $X$. maculatus, A. leuconosticus, $P$. gibbiceps, C. auratus, G. ternetzi, P. tetrazona, P. sphenops, P. reticulata, $P$. innessi, $T$. lalius, $P$. saulosi, and $M$. ramirezi). Infections caused by $A$. veronii were reported in 15 species (D. rerio, X. helleri, P. reticulata, L. ceruleus, $X$. maculatus, P. kahli, A. leuconosticus, P. gibbiceps, T. trichopterus, C. auratus, G. ternetzi, P. tetrazona, P. sphenops, $P$. innessi, and P. saulosi,). A. caviae and A. media were recorded in P. reticulata and P. saulosi, whereas $A$. media were revealed in $T$. trichopterus and $M$. opercularis. The most frequently identified species in our study, A. veronii and A. hydrophila, were mainly isolated from ulcers.

Among the Pseudomonas species recovered from diseased fish, $P$. anguilliseptica is considered the most significant pathogen for cultured fish (3). Pseudomonas spp. is commonly isolated from ornamental fish $(23,25)$. In our study, diseases caused by different species of the genus Pseudomonas affected seven fish species (D. rerio, $X$. helleri, L. caeruleus, X. maculatus, T. trichopterus, G. ternetzi, and P. innesi). Pseudomonas spp. is a member of the normal bacterial flora of fresh water, often acting as an opportunistic pathogen to fish under stress conditions. A number of factors contribute to outbreaks of bacterial diseases, of which poor water quality, overcrowding, and stress are most common in aquaria (23).

Inappetence, skin ulcers, darkening of the skin, exophthalmia, and ascites were reported in outbreaks of S. putrefaciens infection $(1,13,14) . S$. putrefaciens and $S$. baltica are considered inhabitants of marine and brackish water (22); however, in this study, 26 strains of
Shewanella were isolated from 11 fresh water fish species (D. rerio, $P$. reticulata, $X$. maculatus, A. leuconosticus, T. trichopterus, C. auratus, P. tetrazona, C. macracanthus, M. opercularis, $P$ saulosi, and $M$. ramirezi) with symptoms as mentioned above. Relatively recently, $S$. putrefaciens was reported for the first time in freshwater fish in Poland (14). Now, both these Shewanella species seem to be common pathogens of ornamental and pond-raised fish in Poland (22).

Edwardsiellosis has rarely been identified as a significant pathogen to ornamental fish. E. ictaluri was identified as causing disease in the green knife fish (Eigenmannia virescens), rosy barbs (Puntius conchonius), and zebrafish (D. rerio) (5). Both E. ictaluri and E. tarda were isolated from fighting fish (Betta splendens) (27). Edwardsiellosis caused by E. tarda is a disease with many symptoms, like loss of pigmentation, exophtalmia, and spiral movement (21). In this study, abnormal swimming in a parrot cichlid and lesions in internal organs were observed. E. tarda and also $A$. caviae were identified in this case of disease.

Cases of diseases caused by Citrobacter spp. have been described on more than one occasion in literature $(19,25)$. In our study, strains of this genus were isolated from G. ternetzi, S. discus, M. opercularis, T. albonubes, $P$. sphenops, and $P$. scalare, in this last fish in coexistence with the $C$. braakii strain. Emaciation and apathy were the main symptoms of coinfections of Citrobacter spp. Although $C$. freundii and $C$. braakii are commonly isolated fish pathogens (19), C. murliniae had not yet been described in the context of fish infections. In our study, C. murliniae was recovered from ulcers of $C$. auratus with other bacterial species, such as $A$. veronii, A. hydrophila, $C$. freundii, and $S$. ureilytica. $S$. ureilytica is a novel species in the genus Serratia, first isolated from freshwater fish in India (4). There is no available information about its pathogenicity for aquatic organisms; however, the genus is classified as a fish pathogen. 
There are reports of pathogenicity of $P$. shigelloides to fish (17). P. shigelloides can occur as natural intestinal flora of fish, but in case of stress conditions the following symptoms are observed: darkening of body, haemorrhaging, fin rotting, ascitic fluid in the abdominal cavity, and lesions in internal organs (17). In this study, coinfection with Aeromonas spp. was observed. Six strains of $P$. shigelloides were isolated from the two fish species: $D$. rerio and $T$. trichopterus.

The presence of the atypical bacteria: P. rettgeri, $B$. aquatica, and $R$. erythropolis among the isolates is interesting. These species were isolated from the liver and kidneys of $S$. discus with emaciation and darkening of skin. B. aquatica was isolated from surface and sewage water (24), but it is considered to be nonpathogenic for humans and animals. There is no description of disease caused by $R$. erythropolis in ornamental fish. Available reports of $R$. erythropolis infections in fish are related to its presence in Atlantic salmon (Salmo salar L.) (18). Recent reports about $P$. rettgeri pertain to its occurrence in Lagocephalus pufferfish known as fugu (26).

L. anguillarum (earlier known as Vibrio anguillarum) is described as the causative agent of vibriosis among marine and freshwater fish (9). In this study L. anguillarum was isolated from C. macracanthus with no specific symptoms.

Many of these bacteria have pathogenic significance for humans. Species of Aeromonas are responsible for infections of the skin, urinary tract, and posttraumatic wounds (16). Citrobacter spp. is a causative agent of brain abscess and meningitis in neonates (2) and intestinal and urinary tract infections have also been reported (10). Shewanella spp. can cause dangerous infections: one case of monomicrobial $S$. putrefaciens infective endocarditis and several cases of osteomyelitis have been diagnosed $(6,7,11)$. $P$. shigelloides and $P$. rettgeri have been associated with gastroenteritis and diarrhoea in travellers who have ingested contaminated water or food (8). Species representing the genus Pseudomonas were isolated from blood, urine, and sputum of affected patients (29). All these pathogens can cause bacteraemia, especially in immunocompromised persons.

The obtained results indicate that infections with Aeromonas are the most common in aquaria and in many cases coexist with infections with other pathogenic bacteria. In most cases, several types of bacteria were isolated from one individual. In this situation, determination of the causative agent of disease can be difficult without conducting a challenge test. The biodiversity of microorganisms inhabiting aquarium tanks in Lublin and infecting fish is high and includes many strains of bacteria. The presence of exotic, atypical bacteria in aquaria increases the risk of infections among people who take care of ornamental fish.

In conclusion, numerous bacterial strains colonising freshwater ornamental fish in the Lublin region of Poland were identified. The identification of
Aeromonas spp., S. putrefaciens, P. shigelloides, Acinetobacter spp., and Citrobacter spp. in ornamental fish is important due to the zoonotic potential of these bacteria.

Conflict of Interests Statement: The authors declare that there is no conflict of interests regarding the publication of this article.

Financial Disclosure Statement: This article was financed by the Faculty of Veterinary Medicine, University of Life Sciences in Lublin.

Animal Rights Statement: This study was performed with permission of the Local Ethics Committee in Lublin (No. 1/2015).

Acknowledgments: Species identification by MALDITOF MS was performed in the Department of Epizootiology and Clinic of Infectious Diseases of the Faculty of Veterinary Medicine, University of Life Sciences in Lublin.

\section{References}

1. Altun S., Büyükekiz A.G., Duman M., Özyiğit Ö., Karatas S., Turgay E.: Isolation of Shewanella putrefaciens from goldfish (Carassius auratus auratus). Isr J Aquacult-Bamid 2014, 66, 956-962.

2. Badger J.L., Stins M.F., Kim K.S.: Citrobacter freundii invades and replicates in human brain microvascular endothelial cells. Infect Immun 1999, 67, 4208-4215.

3. Berthe F.C.J., Michel C., Bernadet J.F.: Identification of Pseudomonas anguilliseptica isolated from several fish species in France. Dis Aquat Org 1995, 21, 151-155.

4. Bhadra B., Roy P., Chakraborty R.: Serratia ureilytica sp. nov., a novel urea-utilizing species. Int J Syst Evol Micr, 2005, 55, 2155-2158.

5. Blazer V.S., Shotts E.B., Waltman W.D.: Pathology associated with Edwardsiella ictaluri in catfish Ictalurus punctatus Rafinesque, and Danio devario (Hamilton-Buchanan, 1822). J Fish Biol 1985, 27, 167-175.

6. Carlson R.M., Dux K.: Shewanella putrefaciens, a rare cause of osteomyelitis. Int J Low Extrem Wounds 2013, 12, 231-233.

7. Constant J., Chernev I., Gomez E.: Shewanella putrefaciens infective endocarditis, Braz J Infect Dis 2014, 18, 686-688.

8. Escobar J.C., Bhavnani D., Trueba G., Ponce K., Cevallos W., Eisenberg J.: Plesiomonas shigelloides infection, Ecuador, 2004-2008. Emerg Infect Dis 2012, 18, 322-324.

9. Frans I., Michiels C.W., Bossier P., Willems A., Lievens B., Rediers H.: Vibrio anguillarum as a fish pathogen: virulence factors, diagnosis and prevention. J Fish Dis 2011, 34, 643-661.

10. Gill M.A., Schutze G.E.: Citrobacter urinary tract infections in children. Pediatr Infect Dis J 1999, 18, 889-892.

11. Guinetti-Ortiz K., Bocanegra-Jesús A., Gómez de la Torre-Del Carpio A.: Osteomyelitis due to Shewanella putrefaciens: case report and literature review. Medwave 2016, e6642. doi: 10.5867/medwave.2016.10.6642

12. Karczewska-Golec J., Kochanowska-Łyżen M., Olszewski P., Bałut M., Moskot M., Piotrowski A., Golec P., Szalewska-Pałasz A.: Draft genome sequence of Flavobacterium sp. 316, a Baltic Sea isolate exhibiting a high level of resistance to marine stress conditions. Genome Announc 2016, 4, 1-2. 
13. Korun J., Akgun-Dar K., Yazici M.: Isolation of Shewanella putrefaciens from cultured European sea bass, (Dicentrarchus labrax) in Turkey. Rev Med Vet 2009, 160, 532-536.

14. Kozińska A., Pękala A.: First isolation of Shewanella putrefaciens from freshwater fish - a potential new pathogen of fish. B Eur Assoc Fish Path 2004, 24, 199-203.

15. Kozińska A., Pękala A., Grawiński E.: New bacterial infections that have emerged in fish in Poland, Med Weter 2015, 71, 548-552.

16. Lamy B., Kodjo A., colBVH Study Group, Laurent F.: Prospective nationwide study of Aeromonas infections in France. J Clin Microbiol 2009, 47, 1234-1237.

17. Liu Z., Ke X., Lu M., Gao F., Cao J., Zhu H., Wang M.: Identification and pathological observation of a pathogenic Plesiomonas shigelloides strain isolated from cultured tilapia (Oreochromis niloticus). Wei Sheng Wu Xue Bao, 2015, 55, 96-106.

18. Muñoz Perdiguero G., Barrientos A., Madrid E., Birkbeck T.H.: Isolation of Rhodococcus erythropolis from vaccinated Atlantic salmon, Salmo salar L., smolts in Chile. J Fish Dis 2011, 34, 715-717.

19. Nawaz M., Khan A.A., Khan S., Sung K., Steele R.: Isolation and characterization of tetracycline-resistant Citrobacter spp. from catfish. Food Microbiol 2008, 25, 85-91.

20. Olivier K.: World trade in ornamental species. In: Marine Ornamental Species, edited by Cato J., Brown C., Blackwell Publishing, Ames Iowa, 2003, pp. 49-64.

21. Park S.B., Aoki T., Jung T.S.: Pathogenesis of and strategies for preventing Edwardsiella tarda infection in fish. Vet Res 2012, 43, $1-11$.

22. Pękala A., Kozińska A., Paździor E., Głowacka H.: Phenotypical and genotypical characterization of Shewanella putrefaciens strains isolated from diseased freshwater fish. J Fish Dis 2014, 38 , 283-293.

23. Sasmal D., Banerjee T., Bandyopadhyay S., Abraham T.J.: Antibiotic sensitivity of bacterial flora associated with ornamental fish. Indian J Fish 2004, 51, 245-249.

24. Schubert R.H., Groeger-Söhn S.: Detection of Budvicia aquatica and Pragia fontium and occurrence in surface waters. Zentralbl Hyg Umweltmed 1998, 201, 371-376.

25. Trust T.J., Barlett K.H.: Occurrence of potential pathogens in water containing ornamental fishes. Appl Microbiol 1974, 28, $35-40$.

26. Tu N., Tu Q., Tung H., Hieu D., Romero-Jovel S.: Detection of tetrodotoxin-producing Providencia rettgeri T892 in Lagocephalus pufferfish. World J Microbiol Biotechnol 2014, 30, 1829-1835.

27. Vandepitte J., Lemmens P., de Swert L.: Human edwardsiellosis traced to ornamental fish. J Clin Microbiol 1983, 17, 165-167.

28. Verner-Jeffreys D.W., Welch T.J., Schwarz T., Pond M.J., Woodward M.J.: High prevalence of multidrug-tolerant bacteria and associated antimicrobial resistance genes isolated from ornamental fish and their carriage water. PLOS ONE 2009, 4, $1-9$.

29. Von Graevenitz A., Weinstein J.: Pathogenic significance of Pseudomonas fluorescens and Pseudomonas putida. Yale J Biol Med 1971, 44, 265-273.

30. Zanoni R.G., Florio D., Fioravanti M.L., Rossi M., Prearo M. Occurrence of Mycobacterium spp. in ornamental fish in Italy. J Fish Dis 2008, 31, 433-441. 